Pucara, $\mathrm{N}^{\circ} 29,91-118,2018$

https://publicaciones.ucuenca.edu.ec/ojs/index.php/pucara/issue/archive

\title{
Pensar la paz... sólo cuando tenga la tierra
}

\section{Think peace... Just when i have the earth}

Acho que a paz... somente quando ter você terra

\author{
Julie Manuela Mena \\ Investigadora independiente \\ Bogotá-Colombia
}

E-mail: julme87@hotmail.com

\section{Resumen $^{8}$}

En este texto se exponen algunos de los hechos históricos más relevantes en el proceso de introducción de la agroindustria del monocultivo de palma de aceite en el municipio de Tumaco, Nariño, el cual desde sus inicios estuvo relacionado con hechos violentos de desplazamiento forzado, amenazas y persecuciones a campesinos que se negaron a vender sus tierras, quienes finalmente se convirtieron en jornaleros dejando de producir sus propios alimentos para comprarlos, hasta que la plaga que secó la palma y los dejó en el limbo. Razón por la cual la premisa que motiva este análisis es que no es posible pensar el posconflicto en el marco de las actuales negociaciones de paz entre la guerrilla y el gobierno nacional en La Habana, mientras la tierra de campesinos, afrodescendientes e indígenas siga estando en prenda en nombre del desarrollo.

8 El presente artículo es extraído de mi investigación de pregrado en Antropología realizada entre 2011 y 2012, la cual es una aproximación a los impactos que sobre la soberanía alimentaria y los territorios colectivos de las comunidades afrodescendientes ubicadas en la parte alta del río Mira, en el municipio de Tumaco, Nariño, produjeron sucesivos procesos económicos de tipo extractivo desde el siglo XIX, y la explotación agroindustrial del monocultivo de palma aceitera, hoy devastada por una plaga, y que desde sus inicios estuvo muy ligada a hechos violentos en la zona. 
Palabras clave: Palma aceitera, monocultivo, afrodescendientes, territorio colectivo.

\section{Abstract}

In this paper some of the most relevant historical facts are exposed in the process of entering the agribusiness monoculture oil palm in the municipality of Tumaco, Narino, which since its inception was related to violent acts of forced displacement, threats and persecution of peasants who refused to sell their land, who finally became laborers leaving their own food to buy, until the plague that wiped the palm and left in limbo. Why the premise that motivates this analysis is that it is not possible to think about the post-conflict within the framework of the ongoing peace negotiations between the guerrillas and the national government in Havana, while the land of peasants, Afro-descendants and indigenous people continue to be in pledge in the name of development.

Keywords: Oil palm, monoculture, African descent, collective territory.

\section{Resumo}

Neste artigo alguns dos fatos históricos mais relevantes estão expostos no processo de entrada no óleo de palma monocultura do agronegócio no município de Tumaco, Nariño, que desde a sua criação foi relacionada a atos violentos de deslocamento forçado, ameaças e perseguição dos camponeses que se recusaram a vender suas terras, que finalmente tornou-se trabalhadores que deixam a sua própria comida para comprar, até que a praga que dizimou a palma da mão e deixou no limbo. Por que a premissa de que motiva esta análise é que não é possível pensar no pós-conflito, no quadro das negociações de paz em curso entre os guerrilhei- ros eo governo nacional em Havana, enquanto a terra dos camponeses, afro-descendentes e povos indígenas continuam a estar em prometer em nome do desenvolvimento.

Palavras-chave: Óleo de palma, monocultura, ascendência Africano, território coletivo.

\section{Introducción}

Esta investigación tuvo lugar en el municipio de Tumaco, en el caserío rural de Imbilí Carretera -perteneciente al territorio colectivo del Consejo Comunitario Alto Mira y Frontera99-, en Candelillas y La Espriella, veredas que no hacen parte del consejo comunitario en cuestión, buscando de esta forma establecer un análisis comparativo, o lo que en Antropología se llama un estudio "multi-situado".

El análisis giró entonces alrededor de dos momentos que definí como cruciales en la agroindustria palmera en Tumaco, los cuales están "determinados" por la aparición de la Pudrición de Cogollo (PC), plaga que devastó casi la totalidad de las miles de hectáreas sembradas con este monocultivo. Esto es, que la PC establece una transición en el proceso productivo de esa economía y especialmente sobre la producción alimentaria local: del apogeo económico y productivo desde los años 80 del siglo XX, hacia su rotundo deceso en el nuevo siglo; un antes y un

9 Las comunidades afrodescendientes en Colombia se encuentran organizada en territorios de carácter colectivo reconocidos jurídica y legalmente por la ley 70 de 1993 como consejos comunitarios 
después de la Pudrición de Cogollo.

La agroindustria de palma aceitera en Colombia ha significado grandes transformaciones en la geografía humana, en el uso de la tierra y sobre todo en los sistemas de producción campesina. Transformaciones estas que para el caso del Pacífico sur, se han venido estructurando desde los años 60 junto con la arremetida de una creciente ola de violencia exacerbada hacia los años 90 y manteniendo su visceralidad hasta la actualidad.

Debido a la envergadura de los contextos, los actores y los diversos impactos que implica el estudio de esta temática, hasta ahora todavía poco explorada por la disciplina antropológica, es cada vez más complejo pretender agotar el análisis en toda su extensión. Por lo tanto, ese no es el objeto de este artículo. Realmente mis reflexiones son una extensión de las conclusiones de otros investigadores y todas las personas que me colaboraron con sus testimonios, su tiempo y sus conversaciones acerca de este caso específico. Aspectos cruciales para el desarrollo de esta investigación y que antes no había considerado sólo fueron posibles a través de esas conversaciones enriquecidas por la amabilidad y la grandilocuencia de las gentes del Pacífico sur nariñense.

Cabe aclarar que procurando preservar la seguridad de las personas que me colaboraron con sus testimonios, relatos e historias de vida, he modificado sus nombres en las entrevistas citadas en este escrito, debido a los temas sensibles que se abordan en el contexto de la problemática en sí

\section{El Tumaco no Pacífico}

Camino hacia Tumaco son varias cosas las que uno puede observar con curiosidad: Casi toda la vía panamericana está militarizada; son kilómetros de kilómetros de oleoductos de Ecopetrol que vienen desde Orito (Putumayo) hasta el puerto en Tumaco; y tal vez lo más impresionante, los interminables desfiladeros de los cementerios de palma aceitera, que es en lo que prácticamente se han convertido las plantaciones por la devastación que provocó la peste de la Pudrición de Cogollo (PC). (Diario de campo, mayo 2011).

Tumaco es un municipio ubicado en la costa Pacífica del departamento de Nariño a 2 metros sobre el nivel del mar, con una temperatura promedio de $29^{\circ} \mathrm{C}$, una extensión territorial de $3.778 \mathrm{~km}^{2}$ y una población de 183.006 habitantes. De acuerdo con el $\mathrm{CCAI}^{10}$ (2011) el 54,2\% habita en la zona urbana y el 45,8\% en la zona rural. Existen 15 Consejos Comunitarios pertenecientes a la Red de Consejos Comunitarios del Pacífico Sur (RECOMPAS), 12 Resguardos indígenas de los pueblos Awá y Eperara Siapidara que ocupan el 48,21\% y el $18,26 \%$ del territorio, respectivamente.

Después de Buenaventura, es el segundo puerto más importante del pacífico colombiano, y al ser parte de esa vasta región llamada Chocó biogeográfico, presenta un clima tropical húmedo con precipitaciones constantes en un rango que va desde los 3500 a $4500 \mathrm{~mm}$ anuales (CC Alto Mira y Frontera 2003, 9), condiciones estas, entre muchas otras, que explican la singularidad de su riqueza biodiversa en especies de flora y fauna, única en el mundo. Sin embargo, esa misma diversidad natural ha convertido a esta región del Pacífico sur en un objetivo estratégico para la incursión de las economías extractivas del mercado neoliberal, la colonización de la agroindustria nacional, y la invasión del narcotráfico yuxtapuesto a la arremetida de los actores armados del conflicto interno. Testimonio de ello ha sido la extensiva explotación de tagua, caucho y la industria maderera durante poco menos de un siglo por parte del capital extranjero, y los megaproyectos agroindustriales del capital nacional como la producción industrial de camarón y el monocultivo de palma aceitera, los cuales a pesar de las catastróficas plagas y los gravísimos impactos ambientales y económicos que han acarreado para la zona, siguen vigentes hoy en día. En ese sentido, el arribo de esos capitales ha

10 Centro de Coordinación de Acción Interagencial que hoy es el Centro de Coordinación de la Política de Consolidación Territorial (PCT) CCAI-Colombia (2011). 
estado muy ligado con el aumento de los hechos violentos de desplazamientos y homicidios selectivos en la región.

La privilegiada ubicación de Tumaco sobre el mar y los caudalosos ríos que bañan su territorio caracterizan sus principales actividades económicas como la pesca artesanal, la minería, la agricultura y el comercio formal e informal. No obstante el papel fundamental de Tumaco como puerto en la generación de divisas para la economía aduanera del país, es una de las tantas regiones que no aparece dentro del mapa, o por lo menos dentro del de una política soberana del Estado Social de Derecho. Esto se ha hecho manifiesto desde los albores de la República cuyo centralismo político determinó desde un principio la marginalidad en la que ha permanecido relegada esta región del Pacífico sur colombiano de cualquier proyecto de inversión social y de una presencia estatal diferente a la militar y la extractiva. Es así a tal punto que hasta el día de hoy la región no cuenta con las condiciones propicias para ejercer sus más elementales derechos, lo cual se hace visible tanto en la ciudad como en las zonas rurales donde se concentran aún más los altos índices de violencia y de mortalidad infantil por desnutrición, los servicios básicos son casi que inexistentes, el desempleo arrecia, la pobreza es una constante, los sistemas de acueducto y alcantarillado son totalmente deficientes, la atención en el sector salud es insuficiente y las vías de acceso al territorio rural son pésimas.

Aproximadamente hacia el kilómetro 25 de la vía panamericana, hay una zona a la que le llaman "El Tigre" que es el terror de los transeúntes. Es el asilo de miles de N.N., una fosa inmensa a donde va a parar la gente desaparecida, secuestrada, amenazada o señalada como objetivo militar de algún grupo armado ilegal de todos los que hacen presencia en la región. El lugar está lleno de manglar, es un territorio de nadie. Cuentan que los concheros y piangüeras que van a los manglares a recoger piangua, se han encontrado varias veces con restos humanos. Al parecer nunca el CTI de la Fiscalía ha abierto una investigación en esa zona. Todos le temen a ese lugar por lo desolado y hay muchas leyendas creadas a su al- rededor. Según se dice, a algunos conductores les ha pasado que cuando transitan por ahí, sienten que alguien se les sube en sus carros o en sus motos de pasajero. Resulta que si se desaparece alguien de Tumaco, lo van a buscar allí (Diario de campo, 21 de junio de 2011).

En el año 2009, el Observatorio del Delito en Tumaco informó para este municipio de 160.000 habitantes 277 homicidios. En el año 2010 todavía fueron 230, lo que equivale a una tasa de más de 142 homicidios por cada 100.000 habitantes, cuando el promedio nacional es de 32 homicidios. Es decir: En el municipio de Tumaco son asesinadas en promedio 4.4 veces más personas que en el resto del país (Diócesis de Tumaco 2011, p. 52).

Por su parte el informe Forensis (2010) del Instituto Nacional de Medicina Legal y Ciencias Forenses arroja los siguientes resultados sobre los asesinatos en Tumaco para ese año por casos y tasas, así como por género: 223 casos de homicidios masculinos, lo cual representa una tasa de 248,02 homicidios por cada 100.000 habitantes. Los casos de feminicidios fueron 22 los cuales representan una tasa de 24,69 homicidios por 100.000 habitantes. Son 245 casos totales y una tasa total de 136,87 .

A pesar de que La Violencia (años 50) no tuvo impactos tan radicales en esta región como sí sucedió en el resto del país, su escalonamiento en fechas posteriores sí configuró un escenario imprescindible en la historia de otros procesos importantes como la explotación de maderera y camaronera, y el narcotráfico en la actualidad. La llegada tardía de La Violencia al Pacífico sur, significó que los pobladores de la carretera, los ríos y demás zonas rurales, emigraran hacia Ecuador y hacia la cabecera del municipio de Tumaco, mayoritariamente, a la vez que se iban propagando milicias subversivas como los "pájaros" que llegaron a sembrar el terror en las vidas y los oficios de la gente, transformando el uso y la apropiación de los espacios cotidianos al propiciar los primeros asesinatos y desplazamientos (Hoffmann 1999). "Ahí empezó, desde los años 1950-60, la expansión de las grandes ganaderías y plantaciones de palma africana que adquirieron la tierra por medios no siempre legales ni 
pacíficos" (Ibíd., p. 268).

"[...] aquí hubieron [sic.] ganaderos también de Cartago-Valle, del Valle de todas esas partes, primero fueron ellos y después comenzaron las empresas palmicutoras. Lo único que hacían ellos era decirle, 'dígale a la gente que venda, que venda eso y le damos tanto y que venga a la empresa'; y los que no vendían entonces lo sacaban también, buscaban su matraca y los mataban y ¿usted qué hacía? Pues irse”. (Entrevista con líder comunitario 1, Consejo Comunitario Alto Mira y Frontera. Tumaco, 14 de junio 2011).

Después de 9 años de haberle declarado la guerra a los cultivos de coca a través de las fumigaciones con glifosato y de haber desencadenado innumerables devastaciones ambientales envenenando los bosques nativos, los cultivos de pan coger y los ríos, perjudicando la soberanía alimentaria de las familias vecinas y productoras de los cultivos de hoja de coca, durante la primera fase del plan, los resultados no son muy alentadores. El municipio es hoy el mayor productor de coca con 5.025 hectáreas y el mayor productor de cocaína representado por el $21 \%$ del total nacional (SIMCI 2010 citado en CCAI-Colombia 2011).

Los procesos de titulación colectiva emprendidos por los consejos comunitarios empezaron a reñir con el despliegue del Plan Colombia, en estos términos el concepto propiedad colectiva pierde valía cuando las tierras están invadidas por coca o por palma o por ganado. No es posible hablar de soberanía alimentaria cuando no hay dónde cultivar, y por lo tanto tampoco de vida digna o de paz si no se tiene garantías de derecho sobre el territorio, así esté estipulado en una ley.

La tradición violenta y corrupta de la historia social, política y económica de Tumaco se intensifica en la década de los 90 con la consolidación de los cultivos de uso ilícito provenientes del Putumayo y el Caquetá, y la arremetida de los grupos armados que se disputan el negocio y el control por el territorio. El estudio de esta época de los 90 en particular, es angular para entender el papel que entró a desempeñar el monocultivo de palma aceitera en este ya convulsionado contexto, teniendo en cuenta todas las transformaciones sociales, económicas y culturales que se estaban desarrollando a nivel nacional y local específicamente. La avanzada de grupos ilegales como el frente 29 de las FARC, el frente Mariscal Sucre del ELN y distintas organizaciones paramilitares como las Águilas Negras, Autodefensas Campesinas de Nariño ACN, Rastrojos y Organización Nueva Generación, a finales de esta década, junto con la expansión de los cultivos de coca, cambian las condiciones de vida tanto en el campo como en la ciudad hacia su detrimento a través de las lógicas del despojo y el terror (Diócesis de Tumaco 2011, 53).

"[...] desde el año 97, 98, grupos alzados al margen de la ley comenzaron a incursionar, después los otros grupos que enfrentaban a esos grupos anteriores, o sea, supuestamente lo que se llamaba el remedio resultó peor el remedio que la enfermedad, entonces eso después se complicó, después ahora ya se generalizó y lo que todo el país tiene, los problemas que tiene todo el país están concentrados acá. Esto no puede ser ajeno a todos esos grupos para conseguir un dinero rápido, fácil y lo que ha traído problemas, muertes, desolación, miseria, desconfianza [...]" (Entrevista con Juan Escrucería, ex Superintendente de la empresa de palma Palmas de Tumaco. 30 de junio de 2011).

Si bien en otras zonas de la geografía colombiana los fenómenos de desplazamiento forzado y violencia ya habían sucedido con anterioridad a los 90, en el Pacífico sur esos episodios se dieron en una forma más aislada, poco visible pero cada vez más creciente, a tal punto que hoy en día muchos lugares, máxime rurales, son ya inaccesibles, etiquetados como zonas rojas, territorio de guerrillas y paramilitares. Y ese es precisamente el caso de los territorios donde fue introducido el monocultivo de palma (como también lo ha sido con otros megaproyectos agroindustriales en otras latitudes de la geografía nacional). La parte alta del río Mira en Tumaco donde se encuentran principalmente las interminables extensiones de palma de aceite ${ }^{11}$ es una de esas zonas críticas en las que el orden

11 Según el Centro de Coordinación de Acción Integral (2011) la reactivación de los proyectos de palma se han llevado a cabo en el Bajo Mira. 
público está regulado por el régimen de los actores armados ilegales y donde la muerte dejó de ser un fenómeno esporádico para lamentablemente normalizarse en la cotidianidad de sus habitantes.

De hecho, cuando por fin pude adentrarme a la zona rural de Tumaco, específicamente en Imbilí y Candelillas a lo largo de la vía panamericana, hubo que tener ciertas precauciones. A bordo de una moto con Mario ${ }^{12}$, emprendimos en mi última semana en Tumaco, viajes muy pedagógicos hacia las veredas durante cuatro y cinco horas aproximadamente, bajo el sol incandescente de junio. A medida que avanzábamos en el camino, yo iba grabando y Mario me contaba muchas cosas que conocía sobre la agroindustria de la palma, explicándome cómo era el proceso de cosecha y recolección del fruto, me indicó a qué empresas y empresarios pertenecían las plantaciones de palma por cantidad de hectáreas, narraba algunas experiencias de proyectos productivos de cacao de la zona, y recordaba hechos históricos muy importantes con respecto a la industria camaronera de los ochenta. Cuando pasábamos por Chilví y Tangareal, me contó que por ser zonas muy peligrosas en donde no podíamos exponernos yendo dos días de seguido en una misma semana, había que dejar un día de por medio para evitar ser advertidos por las suspicacias de los informantes de los grupos armados irregulares (Jóvenes de la zona que colaboran con los ilegales a cambio de dinero). Incluso hubo un momento mientras yo trataba de sortear la interferencia del viento para grabar, Mario inmediatamente me dijo: "Baja la cámara... esta es zona de paramilitares, por acá los muchachos informan... por los pueblos más que todo... lo mismo Imbilí, allá tremendo, por eso mostrar que vas a tomar una foto, que vas a grabar algo...no, es mejor pasar desapercibido." (Diario de campo, 21 de junio de 2011).

Al respecto, López (2008) del Proceso de Comunidades Negras, PCN, señala:

12 Mario es un líder comunitario que fue sacerdote y que conoce muy bien el territorio del Alto Mira, y por lo tanto fue un gran colaborador y guía para mi trabajo de campo, además de ser un entendido en el tema del monocultivo de palma en la zona.
La evolución e intensidad de las acciones violentas en esta región, han estado muy ligadas entre otros aspectos, con la invasión del monocultivo de la palma aceitera en Tumaco, que cobró tan solo entre 1992 y el 2004 lo que en la región calificamos como cinco afro magnicidios con todas las secuelas que esto conlleva sobre un proceso social organizativo en tan corto lapso: Rafael Valencia Camacho; Francisco Hurtado; Hermana Yolanda Cerón Delgado; José Aristides Rivera y, Luciano Castillo.

"Paradójicamente, el inicio de los procesos de titulación de los territorios colectivos y de constitución, ampliación y saneamiento de resguardos indígenas coincidió con la intensificación de la violencia." (Flórez y Millán 2007, p. 98). La introducción de proyectos agroindustriales han generado desplazamientos de las comunidades del Pacífico, aumentando con el reconocimiento del carácter colectivo ancestral de las tierras de los afrocolombianos, estipulado por la ley 70 de 1993 (Escobar 2004). Y más tarde, con la irrupción de los paramilitares, hacia 1999 en Tumaco, se inició una violenta disputa con la guerrilla por el control tanto del territorio, corredor de estupefacientes, como de algunos megaproyectos (Flórez y Millán 2007, p. 239; Escobar 2004). Estos hechos evidencian el espacio geoestratégico que significa el Pacífico colombiano para el capital extranjero y nacional, por su inconmensurable patrimonio natural. De ahí que "los desplazamientos no son aleatorios, sino selectivos y planificados... (Ya que) los mayores desplazamientos se han producido en las zonas destinadas a la realización de grandes proyectos de desarrollo" (Escobar 2004, p. 60), con costes humanos y ambientales muy elevados, sin dejar de lado los grandes costes culturales.

Así lo confirma un líder del Consejo Comunitario Alto Mira y Frontera:

"“...] los primeros desplazamientos [sic.] que hubieron aquí en Tumaco, en Nariño, acá en la costa del Pacífico, fue por la cuestión de la palma fue mucha gente que le tocó salir, irse, otros vender. En ese entonces como no había todavía la ley 70, pero sí había desplazamiento por las empresas palmicultoras de aceite". (Entrevista con líder comunitario 1, Consejo Comunitario Alto Mira y Frontera. Tumaco, 14 de junio 2011). 
Para el 2011, aproximadamente 30 familias había huido del Consejo Comunitario Alto Mira por los enfrentamientos entre la policía antinarcóticos y la guerrilla de las FARC (OCHA 2011 citado en CCAI-Colombia 2011). Sin embargo, el 2009 fue el año que registró la mayor cantidad de desplazamientos en el municipio de Tumaco.

\section{Desplazamiento en Tumaco 2002-2010}

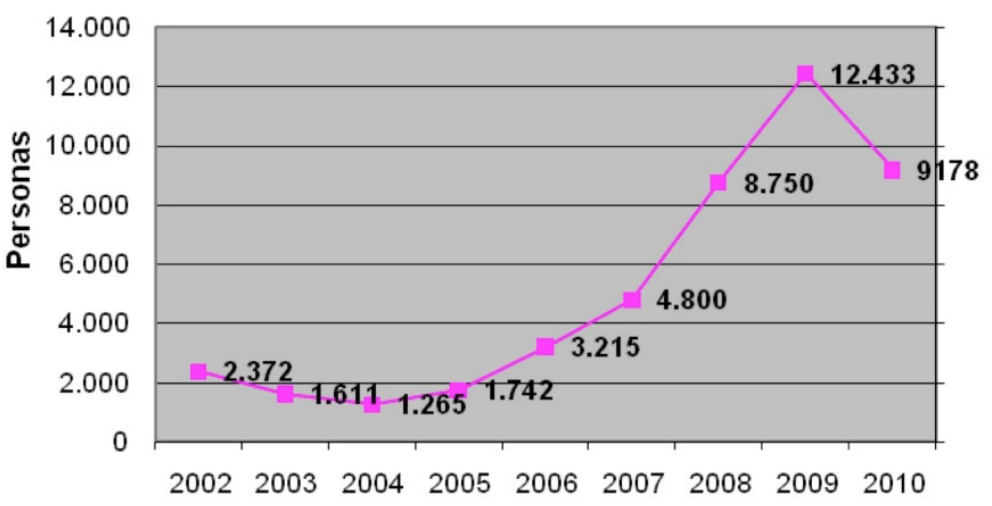

Hacia los años 90 la industria palmera crecía tanto como sus grandes concentraciones de tierra; la expansión de las plantaciones de palma sobre el bosque nativo junto con el cultivo de coca se hizo, en muchos casos, a la fuerza y por expropiación (Escobar 2010, p. 91). La compra de las tierras por sumas ínfimas atropellando la presencia ancestral de las comunidades asentadas en esa región, los fue convirtiendo en jornaleros de sus propias parcelas.
"Hoy en día creemos que casi la mayor parte de las empresas aportan a la violencia, no podemos decir que la financian directamente, pero aportan a la violencia porque si ellos están en un territorio donde ahi está un actor (armado), ese actor así sea a través de la vacuna pero le tienen que dar y si le dan pues también tiene que ofrecerles respaldo (seguridad privada)". (Entrevista con líder comunitario 2, Consejo Comunitario Alto Mira y Frontera. Tumaco, 16 de junio 2011).

Un hecho que empeoró las cosas en la región y traumatizó los primeros pasos del proceso de etnicidad local fue el asesinato del líder comunitario Francisco Hurtado ${ }^{13}$, representante legal del Consejo Comunitario Alto Mira y Frontera. Fue el 12 de febrero de 1997, en la vereda Pital, cuando se encontraba realizando el censo de la población para cumplir con los requisitos exigidos en el proceso de titulación colectiva del consejo comunitario. Para entonces, Francisco ya había denunciado la invasión de territorios ancestralmente habitados por comunidades afro por parte de unas empresas de palma (Diócesis de Tumaco 2009, p. 61; Ramírez 2000; López 2008; Alfonso et al. 2011).

El asesinato de Francisco Hurtado, entonces, derivó en una situación de desconcierto en todos aquellos líderes y dirigentes empeñados en que la ley 70 no se quedara en el papel, sino que fuera el instrumento que les permitiera llevar adelante su plan de vida, es decir conquistar y mantener la autonomía, la autogestión y la promoción de su cultura. (Diócesis de Tumaco 2009, p. 61).

"[...] él era uno de los defensores de esas tierras; y con los mismos sacadores de material de arrastre ya era la pelea, porque el Consejo Comunitario comenzó con los pleitos con las empresas, con los sacadores de materiales ilegales, todo eso... Francisco enfrentó esa situación”. (Entrevista con líder comunitario 1, Consejo Comunitario Alto Mira y Frontera. Tumaco, 13 de junio 2011).

13 El caso de Francisco Hurtado es relatado muy de cerca por Ramírez (2000) en su tesis de pregrado, cuyo trabajo de campo tuvo lugar en la vereda Vuelta de Candelilla de donde era oriundo Francisco, quien se convirtió en amigo de Ramírez ejerciendo un papel guía y orientador muy influyente en su investigación. 
Otro hecho violento se registró en septiembre de 2001, cuando fue asesinada la religiosa Yolanda Cerón Delgado ${ }^{14}$ por sicarios paramilitares frente a la Iglesia La Merced, en el Parque Nariño de Tumaco. Una incesante activista por la justicia social, reclamó los derechos territoriales de los afrocolombianos establecidos en la ley 70/93 y el artículo transitorio 55. Reconocida por su compromiso con la educación y la formación de los niños en la escuela de La Playa de Salahonda, municipio Francisco Pizarro -en la que se empezó a hablar de etnoeducación mucho antes que en otros lugares del país- (Diócesis de Tumaco 2011). Asimismo, fue loable su acompañamiento a las comunidades en sus luchas sociales y étnicas, lo cual la llevó también a hacer graves denuncias, como las alianzas entre la fuerza pública y grupos paramilitares (Alfonso et al. 2011, p. 37).

“[...] a la hermana Yolanda, finada, a ella [...] la mataron por defender los derechos humanos, ella denunció muchos crímenes, claro, la mayor parte de los negros eran las víctimas no hay lugar a dudas. Defender los derechos humanos, ese era el tema fuerte de la Pastoral [...]". (Entrevista con líder comunitario, Recompás. Tumaco, 18 de junio de 2011).

A pesar de las denuncias ante las autoridades, las amenazas y los homicidios de líderes que defienden el territorio colectivo continúan, tal como lo demuestra, una vez más, el asesinato de Armenio Cortés, miembro del Consejo Comunitario Alto Mira y Frontera el 7 de octubre de 2008 (Ibíd.).

Según indicadores tomados en el período de 1998-2008 sobre las zonas donde se han presentado combates entre fuerza pública y guerrillas, y la fuerza pública con autodefensas, delincuencia común y "bandas criminales emergentes", se encuentran muchos municipios que tienen plantaciones de palma. 64 de ellos en medio de combates ente guerrillas y fuerza

$14 \quad$ El ex comandante del Bloque Libertadores del Sur, Guillermo Pérez Alzate alias "Pablo Sevillano" se atribuyó la autoría intelectual del crimen. Disponible en VerdadAbierta.com: "Yolanda Cerón, religiosa de Nariño". Sábado, 17 de octubre de 2009. En: http://www.verdadabierta.com/nunca-mas/1769-yolanda-ceron-religiosa-de-narino [Consultado mayo 2012]. pública y 63 como escenario de los combates de fuerza pública contra los demás actores armados. Sin embargo, según el gremio palmero Fedepalma "el mapa de la violencia en Colombia no coincide con el mapa de la palmicultura nacional" (Rangel et al. 2009, p. 68).

El 2002 fue el año más violento en la historia reciente de Colombia y se supone que el 2007 corresponde al año en que "desaparecieron" las autodefensas AUC, dando inicio a otra oleada de violencia con las llamadas "bandas criminales emergentes" BACRIM, cuya mayor diferencia con las anteriores, según expertos en el tema, es "la ausencia de motivaciones y acciones contrainsurgentes" (Ibíd., p. 72). Sin embargo, se mantienen las disputas con la guerrilla por los controles sobre el negocio del narcotráfico a pesar de las coaliciones pactadas por ambas partes en el marco de sus intereses comunes. De hecho, el territorio de Tumaco se lo han dividido las guerrillas de las FARC y el ELN con los Rastrojos, las Águilas Negras y los Urabeños, en la actualidad, para controlar las rutas de la coca. "Así, la guerrilla se ubica en la parte alta de las carreteras fluviales y los paramilitares en las partes bajas de los ríos, el casco urbano y la zona costera." (Ibíd. p. 79).

Cuando estábamos en Candelillas haciendo una entrevista colectiva a los ex-cultivadores de palma que trabajaron en distintas empresas de la zona del Alto Mira, a pesar de las muchas dudas sobre la pertinencia de una pregunta que deseaba hacerles, sin más vacilación la hice: ¿Qué tanto han afectado los grupos armados del conflicto a la comunidad? Inmediatamente se hizo un silencio sepulcral, nadie parecía siquiera respirar, fue un bloqueo total de la productiva conversación que veníamos manteniendo (Diario de campo, junio de 2011). Sólo fue cuando Ramiro, el más mayor de todos, que parecía no entender la mudez de los demás y como sin esperar a que alguien más hablara, dijo:

"Mire, yo le comento sobre esa materia, aquí tuvimos un caso muy público, eso que, aquí habían muchas muertes hermano... huy hermanito, el río Mira haga de cuenta que el río Mira es un panteón, es un panteón el río Mira... que usted venía subiendo o iba bajando y se encontraba con el muerto, si no se encontraba con el muerto entero se encontraba 
con (los restos)". (Ramiro, antiguo trabajador de Palmas del Mira y pequeño productor de palma. Entrevista colectiva en Candelillas, 28 de junio de 2011).

Partiendo de una génesis histórica y social del monocultivo de la palma aceitera en el país, Mondragón (2007b) señala que "En Colombia los megaproyectos de palma aceitera, como otros, han estado estrictamente asociados a la expansión del paramilitarismo. " Además asegura que la producción de aceite de palma se vincula y se financia con el capital del narcotráfico, lo cual le ha permitido a los socios mayores utilizar el negocio de la palma para el lavado de activos con la aquiescencia del Estado y la comunidad internacional, a través de "exenciones legales y programas de fomento" (Seeboldt y Salinas 2010). Y es que los casos no son pocos, en los que se ha detectado la penetración del paramilitarismo en la agroindustria de la palma. El de Jiguamiandó y Curvaradó en el Urabá chocoano ratificó estas afirmaciones (Roa 2006; WRM 2008; Molano 2010); así como el de Mapiripán en el Meta cuando después de la masacre en 1997 la gente huyó, y en 2002 el Bloque Centauros de los Castaño apoderados, por sus testaferros, de las fincas El Agrado, El Secreto y Madreselva, se convirtieron en grandes productores de palma en esa región. ${ }^{15}$ Otros casos sucedieron en Puerto Wilches donde " $[\ldots]$ se dice que algunas de las cooperativas de las empresas palmeras han sido conformadas por desmovilizados [...]" (Rangel et al. 2009, p. 76). Asimismo, muchas de las empresas de palma se han asentado en tierras de campesinos desplazados o que han sido obligados a venderlas o abandonarlas por presiones de grupos armados utilizados como seguridad privada para sembrar palma, como ha sucedido en Tumaco (Auto 005/2009; Mondragón 2007b; Seeboldt y Salinas 2010; WRM 2008).

15 “Teodosio Pabón Contreras alias 'El Profe', asesor de los Castaño, hoy preso en La Picota, dijo en una entrevista a VerdadAbierta.com que mientras el gobierno negociaba la desmovilización con el Bloque Centauros de las Autodefensas que se consolidó en Mapiripán después de 2002, por debajo de la mesa sus jefes habían diseñado un plan para convertirse en grandes productores de palma de la región. Según Pabón, tenían ya montado un vivero con suficiente plántulas de palma para cubrir cinco mil hectáreas." En VerdadAbierta.com: "El secreto de Mapiripán”, 27 de julio de 2012.
Y aquí no se puede hablar de casos aislados cuando los costes ambientales y sociales repercuten en toda la sociedad colombiana en problemáticas más graves, de tipo económico, político y cultural, por ejemplo, cuando el Estado no es capaz de garantizar la restitución de las tierras ni el retorno efectivo y seguro de las familias desplazadas que migran a las ciudades a mendigar en las calles, sumándose a la mezquina categoría de desplazados y a la interminable lista que configura a Colombia en el segundo país con más desplazados internos después de Sudán. ${ }^{16}$

A lo largo de los recorridos que hacíamos con Mario por las plantaciones nos pudimos dar cuenta que las palmas estaban sembradas inmediatamente al borde de las casas de la gente, viven prácticamente en medio de una y otra palma, es más, tienden sus ropas en las cuerdas que han puesto entre las palmas (Diario de campo, 21 de junio de 2011). Así lo corrobora el líder comunitario de RECOMPAS:

“[...] la gente no tenía tierra ni pa' donde hacer el inodoro, y está la tierra ahí al borde de la casa, de allí en adelante es de los palmeros [...] porque la palma se murió pero ellos son los dueños, la gente ahí no puede sembrar su comida, en su propio territorito, no pueden presentar un proyecto para agricultura porque las tierras que están ellos viviendo no es tierra de ellos, [...] no les queda otra. Pero los palmeros los sacaron de manera sistemática y eso es un problema que tiene que ver con la comida de la gente, la gente no tiene dónde sembrar su comida, ahora como todos son... obreros de la palma, jornaleros de la palma" (Entrevista con líder comunitario, Recompás. Tumaco, 18 de junio de 2011).

\section{Sembrar palma cosechar hambre}

La promoción del monocultivo y su desarrollo se hizo visible, en principio, en el gobierno Pastrana, cuando se abrió paso con el Plan Colombia para continuar extendiéndose con mucha más fuerza en el pasado

16 Audiencia Pública sobre "Extranjerización de la tierra" de la Comisión V del Senado de la República. 1 de noviembre de 2012. 
gobierno Uribe como componente estratégico en la guerra antinarcóticos y contrainsurgente, y en el actual gobierno Santos con los planes de erradicación de la palma muerta y el plan de renovación "Alto Oleico" ${ }^{17}$ a través de una especie híbrida. “... La nueva etapa de cultivo de la palma africana [sic.] empieza en 2002 con las políticas de sustitución de cultivos ilícitos, implementadas por el Gobierno nacional... a través del Plan Colombia" (Rangel et al. 2009, p. 60).

Para el segundo gobierno de Uribe (2006-2010) el Plan Colombia adquiere un nuevo componente en su ofensiva contra el narcotráfico. En esta segunda fase se impulsa el reemplazo de los cultivos de uso ilícito por palma aceitera como la "alternativa social" para generar "empleo y progreso", mientras se "combatía" al narcotráfico con la erradicación química y a los grupos terroristas con el incremento de las operaciones militares abiertas del ejército ya reestructurado y bajo las órdenes del Comando Sur Estadounidense (Pinzón 2007). Sin embargo, los resultados subvirtieron esas proyecciones: masivos desplazamientos forzados, sistemáticas y violentas expropiaciones de tierras a campesinos, indígenas y afrocolombianos, multiplicación de las hectáreas cocaleras, escasez de alimentos, sofisticación de los carteles y las rutas de la droga, aumento de homicidios selectivos, desapariciones, empobrecimiento, encarecimiento del costo de vida.

“(De) esos grandes megaproyectos productivos uno piensa que están pensando en muchos más, uno escucha la propaganda [...], que allí hay que sembrar otros productos, que son supuestamente de alto valor comercial, y entonces eso nos va a molestar de manera muy importante,

17 El plan de renovación de palma de aceite híbrido OxG denominado "alto oleico" se obtiene a través del cruce de palmas de distinto origen la Elaeis oleifera (nativa de centro y sur América) con la Elaeis guineensis jacq (nativa de Guinea, occidente de África), el cual se viene sembrando en Tumaco desde hace 4 años (Cordeagropaz 2011). Se dice y se reitera que este híbrido OxG es tolerante a la PC mas no resistente, sin embargo, ya ha empezado a afectar incluso los viveros de la palma híbrida (Cenipalma 2007) muy significativa la producción de alimentos porque a la gente le han metido la lógica del consumo y la lógica del dinero y esa lógica no ha sido de la cultura de las comunidades negras en el Pacífico, entonces va a cambiar la lógica de la solidaridad para la producción de alimentos propios por la lógica del consumo, por la lógica del enriquecimiento y la lógica del consumo. Y ese consumo no es únicamente comida, es todo lo que ofrece el mercado en el mundo, todo lo que ofrece el consumismo, todo lo que ofrece la televisión, todo lo que ofrece la radio, todo lo que ofrece la propaganda que finalmente es para el crecimiento del capitalismo mas no de las comunidades. Porque una cosa sí sabemos, que el capitalismo necesita más, cada día necesita más pobres porque la pobreza es la razón de ser del capitalismo, entonces cuando el capitalismo empieza a poner sus pies, sus manos y sus sentidos en el Pacífico colombiano, lo único que viene a generar acá es mayor pobreza so pretexto del desarrollo". (Entrevista con líder comunitario Recompás. Tumaco, 18 de junio de 2011).

"El propósito de crecimiento del mercado para obtener beneficios económicos parte de una racionalidad privada e individualista que se supone impacta en el crecimiento de la calidad de vida de la población, lo cual termina por homogenizar sus proyecciones y sus procesos, ignorando la diversidad de capacidades y limitaciones que caracterizan y definen el contexto sociogeográfico en que se desenvuelve esta dinámica. Desde esta perspectiva puede considerarse que el Plan Nacional de Desarrollo Hacia un Estado Comunitario se alinea al Plan Colombia, al ALCA y al TLC.” (Flórez y Millán 2007, p. 122).

Esto sin duda significó nuevas transformaciones a la "geografía humana" a través de migraciones forzadas y voluntarias, muchos de los campesinos convertidos en jornaleros y mano de obra barata, y el señalamiento de líderes comunitarios y civiles que se oponían. La "geografía natural" volvió a enfrentar la deforestación de los bosques nativos, la degradación del equilibrio de los suelos y la contaminación de los ríos (López 2008); y la geografía cultural, en definitiva, estuvo muy perjudicada por el reemplazo que implicó el monocultivo sobre los tradicionales cultivos del pan coger del sistema de producción local, empezando por la generalizada escasez de alimentos imprescindibles en la dieta tradicional. Asi- 
mismo, algunos de los linderos de los territorios colectivos tuvieron que ir reculando al avance expansivo de las plantaciones. Y peor aun cuando llegó la PC, que acabó con cerca del 90\% del área cultivada, empezó a afectar la productividad del aceite, ya algo deprimida, tal vez, por la fumigación de los cultivos ilícitos.

Las grandes transformaciones culturales en la soberanía alimentaria fueron visibles sobre todo en el sentido de la transición que se dio de la lógica de producción propia de los alimentos hacia una lógica de consumo. Situación que se complica, principalmente en las fincas de los pequeños productores de palma, con la vulneración y el truncamiento que sobre las economías locales provoca el fracaso rotundo en los controles sobre la PC, la cual ya incluso está contagiando los viveros y las plantaciones de palma híbrida que hacen parte del plan de renovación de palma de aceite híbrido denominado "Alto Oleico". De hecho, durante los años 90 el cultivo de palma se posicionó como el principal renglón de la economía local y de la inversión capitalista nacional e internacional (Restrepo 2004). Del mismo modo que son cada vez más las gentes que dependen (directamente e indirectamente) de dicha economía.

"[...] como la gente tumbó todo entonces como en ese momento estaba la palma en su producción y estaban empleados tenían que comprarlo todo, todo lo compraban; y algunos que de pronto tenían porque no lo tumbaron todo. Entonces eran fieles esclavos porque trabajaban de lunes a sábado en la empresa y tenían que emplearse ellos el día domingo para poder, ya, apuntalar una mata de plátano (en su propia finca). Pero la relación en cuanto al cultivo de pan coger prácticamente fue una vaina más de, vista más por la parte del inmediatismo, si?, de tener plata para el día sábado o de tener plata para que la mujer esté bien o que mis hijos anden bien o que estudien en un buen lugar, si?, pero que si nos damos cuenta hubieron [sic.] muchos que no pudieron alcanzar, si?, sólo lo conseguían a medias y entonces esa relación se fue perdiendo porque a la gente la fueron culturizando con la vaina del inmediatismo". (Entrevista con líder comunitario 2, Consejo Comunitario Alto Mira y Frontera. Tumaco 16 de junio 2011)
A pesar de que durante unas cuantas décadas la palma resistió trayéndoles abundantes rendimientos a los empresarios y lo necesario para los campesinos productores, no se puede señalar los tiempos de su auge como el vértice de una política agraria basada en el compromiso con las necesidades sociales y económicas de la comunidad del Pacífico nariñense, teniendo en cuenta que en la región se concentran índices muy altos de violencia, corrupción, homicidios, desplazamiento forzado, mortalidad infantil y pobreza. Porque sobre el espejismo en que se erigió el monocultivo de la palma aceitera muy difícilmente se habría podido construir un proyecto de vida social familiar ni mucho menos una economía comunitaria a largo plazo. Desafortunadamente la agroindustria a gran escala en Colombia muy pocas veces ha estado orientada a una transformación real de las condiciones de vida en el campo, a una asistencia técnica y capacitada sin que por medio esté en prenda la tierra, la mano de obra o un endeudamiento tenaz con los bancos, con el vecino de la tienda o el colegio de los niños. Las fracasadas y míseras reformas agrarias año tras año cojean en el sentido vertical de los protocolos demagógicos de sus etiquetas y campañas publicitarias para agrietar cada vez más los abismos entre ricos y pobres, porque el blanco siempre ha sido la tierra del campesino y su mano de obra.

El Pacífico sur colombiano ya no es una región marginal, ha venido siendo "integrada" a la nación a través de una economía extractiva sobre el oro, el caucho y la tagua en un primer momento durante el siglo XIX, y posteriormente sobre la madera, el mangle y el palmito en el siglo XX, por parte de un capital de origen extranjero. Después de la segunda mitad del s. XX comienza a configurarse poco a poco sobre la región una economía de mercado por parte de una agroindustria nacional del sector privado hacia la apertura del capital neoliberal global en la década de los 90 en el gobierno Gaviria, orientada a los monocultivos como la palma aceitera, el camarón en cautiverio, el cacao. Este segundo momento en la política integracionista del Pacífico sur colombiano dentro del sistema económico nacional, constituye una nueva lógica de discriminación, más hipócrita por su corte multiculturalista, 
que una política verdaderamente inclusiva en términos de equidad social, económica y cultural.

Finalmente con el estudio de este caso podemos darnos cuenta que evidentemente los impactos generados por la agroindustria del monocultivo de palma sobre la soberanía alimentaria de las comunidades y los derechos territoriales del Alto Mira son el resultado de la configuración de procesos extractivos anteriores. La escases de algunos de los productos fundamentales de la dieta tradicional en el Alto Mira afectaron la disponibilidad y el acceso a un suministro seguro de alimentos y sobre todo, la capacidad y los medios para producirlos propiamente cuando la lógica del enriquecimiento se consolida sobre la lógica de la solidaridad y la soberanía alimentaria. Por supuesto, los proyectos extractivos y agroindustriales que han marcado la parasitaria historia económica de la región de Tumaco debieron de haber acarreado crisis alimentarias similares de las cuales no se ha encontrado una rehabilitación efectiva por parte de las asociaciones y los gobiernos locales ni por parte de las comunidades y sus líderes, porque frente a las coyunturas políticas caracterizadas por una tradición clientelista y corrupta, y una historia social condenada por un convulsionado orden público, no se han tomado las medidas preventivas que la experiencia permite ni se ha buscado un entendimiento consensuado entre las distintas partes que son las protagonistas de una transformación estructural socio-cultural y económico-política de la región, esto es, las instituciones, los gobiernos y las autoridades locales, las asociaciones públicas y privadas, las comunidades indígenas y afrocolombianas y la sociedad civil en general, sin que ello desestime la responsabilidad y la deuda del Estado nacional con esa zona del país.

\section{Reflexiones finales}

Sin duda el carácter colectivo del territorio del Consejo Comunitario Alto Mira y Frontera se vio tremendamente afectado sobre todo por los conflictos de intereses entre el marco normativo y tributario que promo- ciona la producción del monocultivo de palma y agrocombustibles, que los exime de impuestos y les procura prerrogativas financieras frente a la ley 70 de 1993, el decreto 1745 de 1995 y el artículo transitorio 55 de la Constitución que le confiere a las tierras colectivas de afrocolombianos la calidad de inalienables, inembargables e imprescriptibles.

La escandalosa concentración de tierras en manos de los grandes empresarios sigue sembrando muchas dudas sobre la legalidad de su adquisición cuando observamos las grandes cosechas de desplazamientos masivos de gente humilde. Luego, la agroindustria palmera en Colombia no sólo introduce el monocultivo de palma, impone además una monoeconomía estrictamente capitalista en la que no tienen cabida otros tipos de economías; coloniza con una monocultura basada en los individualismos y la verticalidad plutocrática; radicaliza un monopensamiento empresarial de corte tecnocrático por fuera del cual sólo hay "atraso" y "subdesarrollo".

Para terminar sólo tengo como aporte a las reflexiones finales más preguntas, sobre todo en estos momentos en el marco de la vigencia de 14 TLC's firmados, el Plan Nacional de Desarrollo del presidente Santos, y el proceso de negociaciones en la Habana entre la guerrilla las FARC y el gobierno, muy a propósito de los temas álgidos que se están tocando en la mesa como el actual sistema económico, la concentración de tierras, la situación agraria, sin los cuales no se puede hablar de paz ni de posconflicto.

Teniendo en cuenta que la agroindustria de la palma de aceite sigue siendo un sector en la economía nacional que concentra un importante número de mano de obra, lamentablemente los millones de activos que mueven las empresas palmeras en el procesamiento del aceite de palma y en cuanto a financiación y apoyos tanto nacionales como internacionales y sobre todo en cuanto a exenciones tributarias legalmente estipuladas, no se redistribuyen en mejoras equitativas a largo plazo e inversión social estructural sino meramente coyuntural. No es posible hablar de algún 
tipo de compensación por los impactos ambientales, económicos y socio-culturales que desata la producción de gran escala de los monocultivos agroindustriales, porque es la vida la que está en juego. En estos términos, la agroindustria palmera no puede significar como una alternativa a los cultivos de uso ilícito, ni mucho menos hablar de sostenibilidad, de compromiso social, de rentabilidad, de progreso. Esta política fracasa en su abanderada batalla contrainsurgente y antinarcótica.

Y, finalmente, ¿Es posible que hablar de militarización y violación de derechos humanos se nos haya convertido en un pleonasmo? Cuando a 4 años de implementación del Plan Troya Pacífico por el presidente Santos, los réditos recibidos por esta región tan golpeada por el conflicto armado interno, solo son de abusos, violencia sexual y feminicidios (CCAI 2011)

\section{Referencias bibliográficas:}

Alfonso, T. y Prada, M. (2011). "Estudios de caso: Desarrollo y conflicto de tierras", "Caso 1: Alto Mira y Frontera". En Derechos enterrados. Comunidades étnicas y campesinas en Colombia. Nueve casos de estudio. Julieta Lemaitre (comp.). Centro de investigaciones sociojurídicas, Universidad de los Andes. Ediciones Uniandes. Bogotá. Pp. 13-46.

Audiencia Pública sobre "Extranjerización de la tierra” de la Comisión V del Senado de la República. 1 de noviembre de 2012.

CCAI-Colombia (Centro de Coordinación de Acción Interagencial) (2011). "Tumaco: La marcha de la desesperación". Septiembre 17. Disponible en: http://ccai-colombia.org/2011/09/17/ tumaco-la-marcha-de-la-desesperacion/ [Consultado en marzo de 2015].

Centro de Investigación en Palma (CENIPALMA) (2007). "Taller técnico científico sobre avances y resultados en los procesos de investigación y manejo del complejo Pudrición del Cogollo en Tumaco". Fedepalma, Corpoica, Ministerio de Agricultura y Desarrollo Rural. 24-25 de octubre. Tumaco.

Consejo Comunitario del Alto Mira y Frontera (2003). "Plan de Manejo Integral Ambiental 2003-2013”, San Andrés de Tumaco, Nariño.

CORDEAGROPAZ (2011). Palma de aceite híbrido alto oleico. La alternativa palmera de Tumaco. Con el apoyo de la Oficina de las Naciones Unidas contra la Droga y el Delito (UNODC) y la Agencia Presidencial para la Acción Social y la Cooperación Internacional (Acción Social) - Programa contra Cultivos Ilícitos (PCI). Nariño.

Corte Constitucional (2009) “Auto 005”. Septiembre 30. 
Diócesis de Tumaco (2009). ¡Que nadie diga que no pasa nada! Una mirada desde la región del Pacífico Nariñense. Balance No. 1, Junio, Nariño, Colombia.

\section{(2011). ¡Que nadie diga que no pasa nada! Una} mirada desde la región del Pacífico Nariñense. Balance No. 2, Marzo, Nariño, Colombia.

Escobar, A. (2004) "Desplazamientos, desarrollo y modernidad en el Pacífico colombiano". En: Conflicto e (in) visibilidad. Retos en los estudio de la gente negra en Colombia. Eduardo Restrepo - Axel Rojas (editores). Editorial Universidad del Cauca, Popayán. Pp. 53-72.

(2010) "Capital" en Territorios de diferencia: Lugar, movimientos, vida, redes. Traducción de Eduardo Restrepo. Envión Editores, Colombia. Pp. 89-132.

FORENSIS (2010). Descripción del comportamiento del homicidio Colombia, 2010. Andrea del Pilar Acero Álvarez. Instituto Nacional de Medicina Legal y Ciencias Forenses. Bogotá.

Flórez López, J. y Millán, C. (2007). Derecho a la alimentación y al territorio en el Pacifico colombiano. En colaboración de la Diócesis de Tumaco, la Diócesis de Quibdó, el Vicariato Apostólico de Guapi, la Diócesis de Buenaventura y la Diócesis de Istmina. Colombia.

Hoffmann, O. (1999). "Identidades locales, identidades negras: La conformación del campo político en Tumaco (1950 - 1988)". En: Tumaco. Haciendo ciudad. Odile Hoffmann, Michel Agier, Manuela Álvarez y Eduardo Restrepo. Icanh-IRD-Universidad del Valle. Cali.
López Rodríguez, D. (2008). "Palma aceitera en los territorios de las comunidades negras del pacífico sur colombiano". Proceso de las Comunidades Negras PCN. Archivo digital disponible en: www.semillas.org.co/sitio.shtml?apc $=\mathrm{d} 1 \mathrm{c} 1$ [Consultado en octubre de 2009].

Mena Ortega, J. (2013) El monocultivo de la palma de aceite en la zona del Alto Mira en Tumaco, Nariño. Trabajo de grado. Departamento de Antropología, Universidad del Cauca, Popayán.

Molano, A. (2010). "El Chocó que desconocemos" en El Espectador, 23 de mayo, Bogotá.

Mondragón, H. (2007b). "Colombia, caña de azúcar y palma aceitera. Biocombustibles y relaciones de dominación" Fuente: Prensa Rural. Archivo digital disponible en: http://www. biodiversidadla.org/content/view/full/37696. [Consultado en octubre de 2009].

Ramírez Vidal, L. (2000). Alimentación, territorio e identidad en la vereda Vuelta de Candelilla. Tesis de grado. Departamento de Antropología, Universidad de Antioquia, Medellín.

Rangel, A., Ramirez, W. y Betancur, P. (2009). La palma Africana: Mitos y realidades del conflicto. Fundación Seguridad y Democracia. Bogotá.

Restrepo, E. (2004). "Hacia una etnografía del cultivo de la palma africana en Tumaco" en Universitas Humanística. Vol. XXXI, No. 58. Pontificia Universidad Javeriana. Redalyc. Pp. 72-87.

Roa Avendaño, T. (2006). "Colombia: biodiesel de la palma aceitera". Censat Agua Viva. Boletín 112 del WRM (Movimiento Mundial para los Bosques Tropicales). Archivo digital consultado en noviembre de 2009, disponible en: www.wrm.org.uy/ boletin/112/Colombia.html [Consultado diciembre de 2009]. 
Seeboldt, S. y Salinas Y. (2010). Responsabilidad y sostenibilidad de la industria de la palma. ¿Son factibles los principios y criterios de la RPSO en Colombia? Oxfam Novib e Indepaz. Bogotá.

Pinzón Sánchez, A. (2007). Plan Colombia II. Fuente: ARGENPRESS. Archivo digital disponible en: http://www.biodiversidadla.org/ content/view/full/37707. [Consultado en enero de 2010].

VerdadAbierta.com: "El secreto de Mapiripán", 27 de julio de 2012. [Consultado en agosto de 2012].

VerdadAbierta.com: "Yolanda Cerón, religiosa de Nariño". Sábado, 17 de octubre de 2009. En: http://www.verdadabierta.com/nuncamas/1769-yolanda-ceron-religiosa-de-narino [Consultado mayo 2012].

WRM (Movimiento Mundial para los Bosques Tropicales) (2008). "Colombia: la palma aceitera crece a fuerza de violencia". Boletín No. 132, julio. Archivo digital disponible en: http:// www.wrm.org.uy/boletin/132/Colombia.html [Consultado diciembre 2009]. 